\title{
Damping of Low Frequency Inter-Area Oscillations on Stressed Tie-Line using PSS
}

\author{
Nasri Azhari Dafaalla ${ }^{1}$, Adam Abdullah Adam ${ }^{2}$ \\ Lecturer, Dept. of Electrical Engineering, Kassala University, Kassala, Sudan ${ }^{1}$ \\ Associated Professor, Faculty of Khartoum Technology, Khartoum, Sudan ${ }^{2}$
}

\begin{abstract}
Study of low frequency oscillation is very important in power system stability studies, it is play a vital role in maximum power transfer and optimal power system security. These oscillation concern units on different area on the system and hence may result in a higher oscillation on the tie-line. A solution to this problem is the addition of power system stabilizers on the generators on the power system to the automatic voltage regulator. A two-area system is used to understand the nature of these oscillation and the solution were applied. The low frequency oscillation of concerned are inter-area mode oscillations.
\end{abstract}

Keywords: Inter-area oscillations, Modal Analysis, Mode Shape, Participation Factor, PSS.

\section{INTRODUCTION}

Low frequency oscillations are inherent phenomena of power systems, since electric power systems have non-linear dynamics in nature that's lead to rise of many modes in the system, namely local modes, torsional modes and inter-area modes. Inter-area modes are those in which synchronous generators in one area oscillates against generators in another area, interconnected by a weak tie-line. These oscillations are in the range of 0.1 to $1 \mathrm{~Hz}$. However, the major cause of unstable inter area modes is the increase in synchronizing torque provided by the automatic voltage regulators [4]. The aim of this paper is to discuss the nature of interarea mode and to put the use of PSS to improve the damping of these low frequency oscillations. Two machine system has two generating areas interconnected by a tie line. This system originally created for research report commissioned from Ontario Hydro by the Canadian electric Association [1,2]. Section 2 of this paper provides a brief description on system model. Analytical techniques and the simulation tool used in this work have been presented in Section. Results have been presented in section 4.

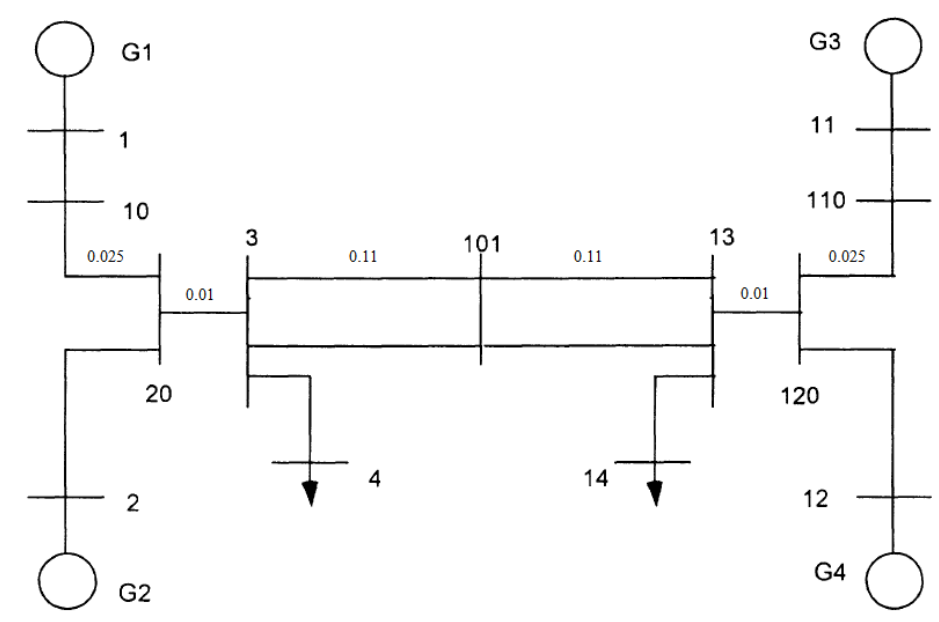

Fig -1: Two-Area system

\section{SYSTEM STRUCTURE AND MODELLING}

Study of inter-area mode requires detailed representation of the system. A single line diagram of the system is shown in Fig. 1. There are two generation and load areas interconnected by a relatively weak transmission line. The basic system formed by two symmetrical operational areas. Each region has two generators. The generators and their controls are identical. The system is quit heavily stressed, it has $400 \mathrm{MW}$ flowing in the tie lines from area 1 to area 2. Dynamic data for generators and excitation system may found in [3]. There are three modes of oscillation presented in this system, two 
local-modes, one in each area, and one inter-area mode, in which generators in one area oscillates against those in the other area.

\section{- Synchronous Generators and Controls}

In power system studies the synchronous generators model vary from a simple classical model to the more detailed ones depending on the accurate dynamics of the system required. As the study deals with low frequency modes, a detailed sub-transient model of synchronous is used in this study [7, 8]. Generators are equipped with simplified static exciters and simplified turbine-governor model.

\section{- Load Modelling}

The system has two loads one at bus4 and bus 14. Static load model has been used. All loads are modelled as $50 \%$ constant current active loads.

\section{ANALYTICAL TECHNEQUE AND TOOL}

A brief discussion on analytical technique used in the analysis and demonstration of simulation tool used has been written below.

\subsection{Analysis Techniques}

Since the study involves oscillations, it's widely in power system studies to use linear analysis. It enables the use of a system model that has been linearized about a steady state operating point. Once we have a linear, the very powerful methods of modal analysis are open to use. The detailed derivation of linearized power system equations is beyond the scope of this work. Detailed model development can be found in references $[8,10]$. Based on these references, a brief review has been presented here. After approximation, the linearized form of power system can be represented by the following equations:

$\Delta \mathrm{x}$ is the state vector of length $\mathrm{n} \times 1$

$\Delta \mathrm{y}$ is the output vector of length $\mathrm{m} \times 1$

$\Delta \mathrm{u}$ is the input vector of length $\mathrm{r} \times 1$

$A$ is the state or plant matrix of size $n \times n$

$B$ is the control or input matrix of $n \times r$

$\mathrm{C}$ is the output matrix of size $\mathrm{m} \times \mathrm{n}$

$\mathrm{D}$ is the feed forward matrix of size $\mathrm{m} \times \mathrm{r}$ Where $\mathrm{n}$ is number of states.

Now, to find the eigenvalues of system state matrix, we use the characteristic equation of the state matrix

$$
\operatorname{det}(\mathrm{A}-\lambda \mathrm{I})=0
$$

Mathematically, for each eigenvalue there is a one set of two orthogonal eigenvectors, namely the right and left eigenvectors, satisfying the following equation

$$
\begin{aligned}
\mathrm{A} \Phi_{\mathrm{i}}= & \lambda_{\mathrm{i}} \Phi_{\mathrm{i}} \\
& \Psi_{\mathrm{i}} \mathrm{A}_{\mathrm{i}}=\lambda_{\mathrm{i}} \Psi_{\mathrm{i}}
\end{aligned}
$$

$\lambda_{\mathrm{i}}$ is the $\mathrm{i}^{\text {th }}$ eigenvalue

$\Phi_{\mathrm{i}}$ is the right eigenvector corresponding to $\lambda_{\mathrm{i}}$

$\Psi_{\mathrm{i}}$ is the left eigenvector corresponding to $\lambda_{\mathrm{i}}$

After applying certain transformation, the $\mathrm{n}$ coupled linear deferential equations of the state matrix transformed to $\mathrm{n}$ decoupled linear differential equations.

Introducing new state vector $\mathrm{z}$ related to the original state vector $\Delta \mathrm{x}$.

$$
\Delta \mathrm{x}=\Phi \mathrm{z}
$$

By made some substitution we get.

Where $\Lambda$ is diagonal matrix of eigenvalues. The modes of oscillation are the solutions to these decoupled equations. Physically, the right eigenvector describes how much each mode of oscillation is distributed among the system states. It is sometimes called mode shape. The left eigenvector, together with the input coefficient matrix and the disturbance determines the amplitude of the mode. 
The oscillatory modes are identified by the complex eigenvalues. Since the state matrix is real, the complex eigenvalues occur in complex conjugate pairs, they expressed as:

A good measure of damping is the damping ratio. It is defined as:

$\zeta$

The real part of a complex eigenvalue indicates whether an oscillations decays (negative real part and negative damping), remains at constant amplitude (zero real part) or growth (positive real part and negative damping).

The Participation Factor is a quit good indication of the importance of state to the mode. In power systems, it is particularly useful as a screen for power system stabilizer placement. Mathematically, the participation factor of the $r^{\text {th }}$ state in the $i^{\text {th }}$ mode is the product of the $\mathrm{r}^{\text {th }}$ element in the $\mathrm{i}^{\text {th }}$ left eigenvector and the $\mathrm{r}^{\text {th }}$ element in the $\mathrm{i}^{\text {th }}$ right eigenvector:

$$
\mathrm{P}_{\mathrm{ir}}=\Psi_{\mathrm{ir}} \Phi_{\mathrm{ri}}
$$

\subsection{Simulation Tool}

Power System Toolbox (PST) version 3.0 has been used for the analysis required by this work. The Power System Toolbox (PST) was conceived and initially developed by Dr. Kwok W. Cheung and Prof. Joe Chow from Rensselaer Polytechnic Institute in the early 1990s. From 1993 to 2009, it was marketed, and further developed, by Graham Rogers (formerly Cherry Tree Scientific Software), and is in use by utilities, consultants and universities worldwide.

PST consists of a set of coordinated MATLAB m-files which model the power system components necessary for power system power flow and stability studies.

\section{RESULT OBTAINED FROM ANALYSIS}

The system under study has been analyzed without PSS and with PSS, the result has been written in the following text.

\subsection{Test Without PSS}

Analysis has been started with stressed system without PSS. About $400 \mathrm{MW}$ transferred from area 1 to area 2.

To excite the different modes of oscillation a step change in $\mathrm{V}_{\text {ref }}$ of the automatic voltage regulator of 0.05 has been applied at generator 1. Both time-domain and modal analysis has been performed under this condition. From modal analysis, there are one system mode with damping less than 0.05 , its damping coefficient and frequency shown in Table 1 .

Table -1: Damping and Frequency of the Critical Mode

\begin{tabular}{ccc}
\hline Eigenvalue & Damping & Frequency \\
\hline 4.029 & 0.011021 & 0.64123 \\
\hline
\end{tabular}

A time-domain analysis has been performed with same condition. The generators speed changes are shown Figure 2 which shows that generators in area 1 oscillates against generators in area 2 . The inter-area oscillation may be seen in all generator speeds.

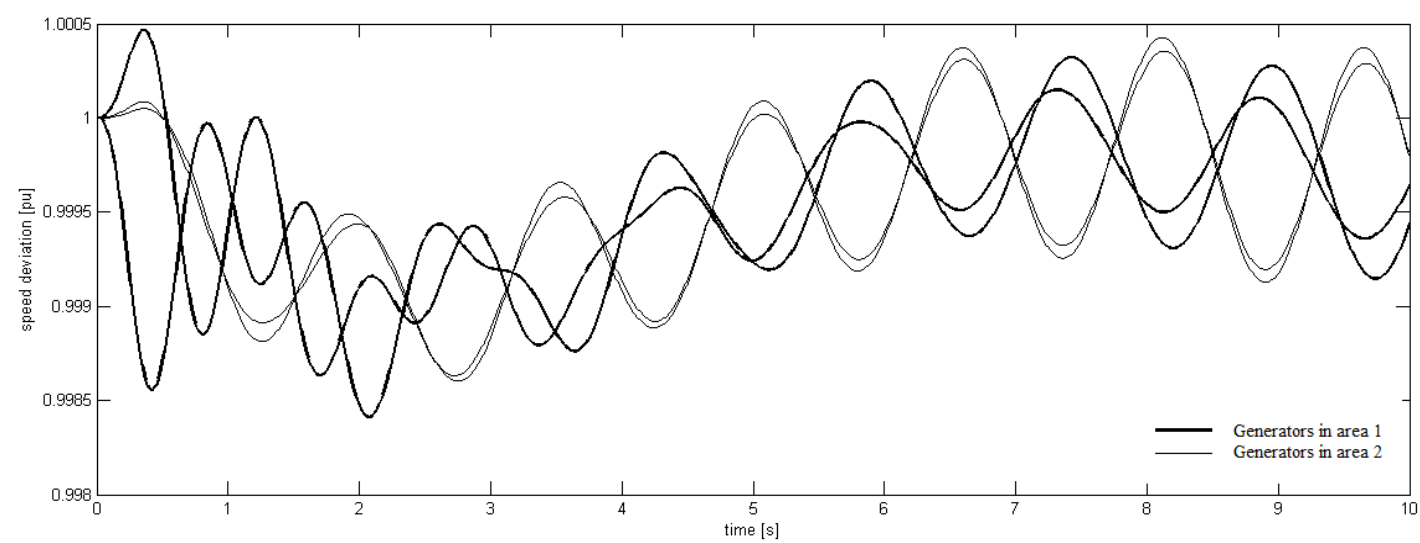

Fig -2: Change in Generators Speed without PSS 


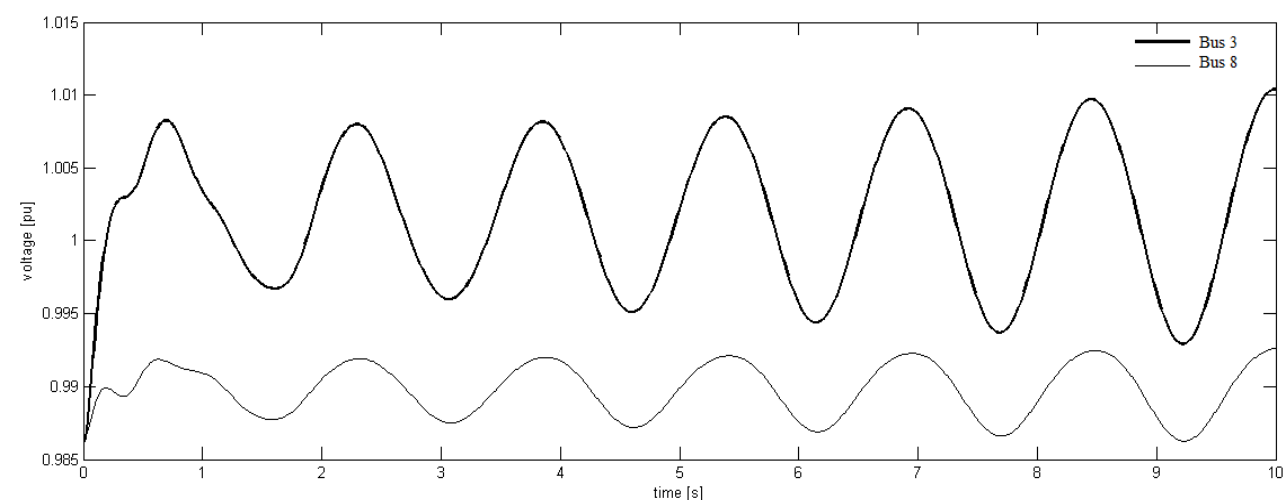

Fig -3: Change in Tie-Line Bus Voltage without PSS

Fig. 3 shows the voltage change in the sending end (Bus 3) and receiving (Bus 13) ends of the tie-line. Both of voltage oscillations are dominated by the inter-area mode.

\subsection{Analysis with PSS}

To test the effect the PSS on the frequency and damping of the inter-area mode we carried out the same analysis with PSS installed on all four generators. The PSS design based on try and error determination of the PSS parameters to fit as closely as desired the ideal phase lead between $\mathrm{V}_{\text {ref }}$ and the generator electrical torque necessary to produce a damping torque over the matched frequency range. From modal analysis, the inter-area mode with PSS is found to be Therefore, the damping is improved from 0.01 to 0.13 . A time-domain analysis has been done once again. The generators speed changes are shown Fig. 4 and tie-line voltage in Fig. 5. It is obvious that the oscillations has been damped.

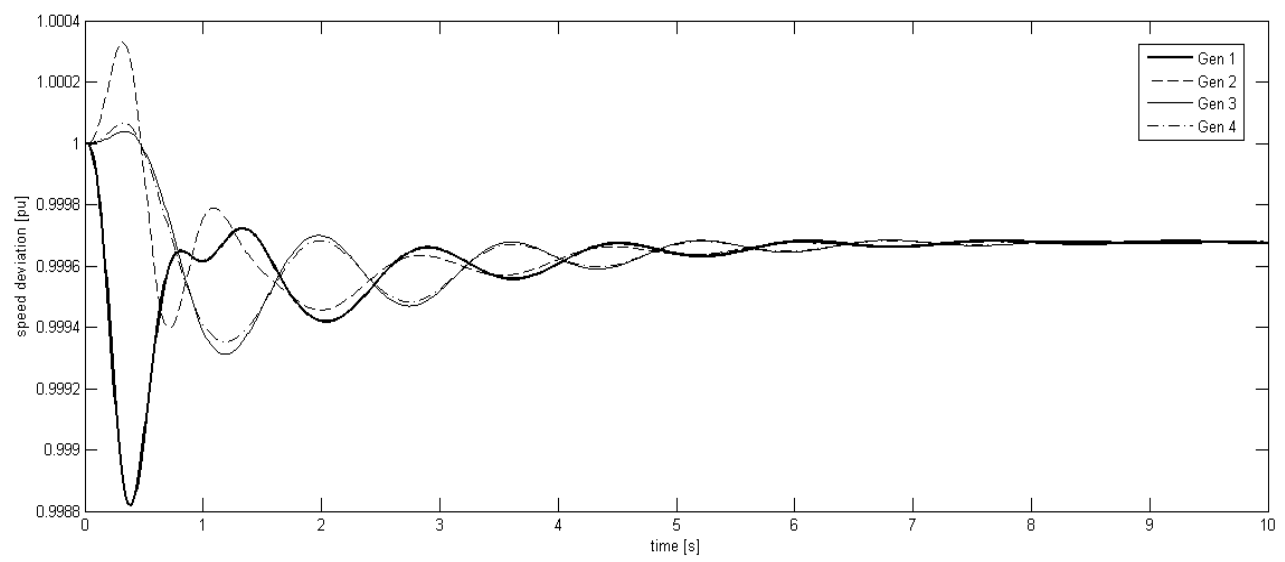

Fig -4: Change in Generators Speed with PSS

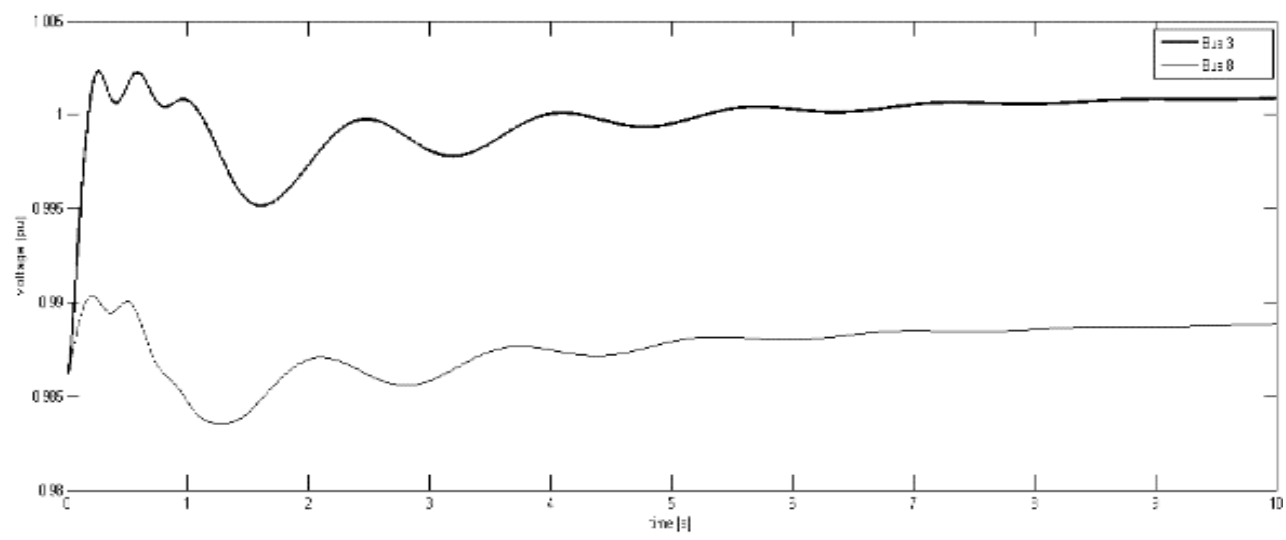

Fig -5: Change in Tie-Line Bus Voltage with PSS 


\section{CONCLUSIONS}

This paper discussed the use of power system stabilizer to damp the inter- area oscillations and hence improve system stability. Application of PSS to the Two-Area System presents that the best result is obtained by installing PSS to all of the 4 generators. Where the damping ratio of the inter-area mode has improved to a satisfactory value.

\section{REFERENCES}

[1] Inter-area Oscillations in Power Systems, IEEE Power Engineering Society, Special Publication 95 TP 101, 1995

[2] J.P. Hauer, DJ. Trudinowski, GJ. Rogers, W.A. Mittelstadt, W.H. Litzenburger, and J.M. Johnston, 'Keeping an eye on power system dynamics', IEEE Computer

[3] M. Klein, G. J. Rogers and P. Kundur, “A Fundamental Study of Inter-Area Oscillations in Power Systems”, IEEE Trans. Power Systems, vol. 6, no. 4, pp. 914-92,1 August1991.

[4] J. Paserba, P. Kundur, J. Sanchez-Gasca, and E. Larsen, "Small Signal Stability and Power System Oscillations", Article 11.3, The Electric Power Engineering Handbook,Florida: CRC Press LLC and IEEE Press, 2001.

[5] M. E. Aboul-Ela, A. A. Salam, J. D. McCalley, and A. A.Fouad, "Damping Controller Design for Power System Oscillations Using Global Signals, IEEE Trans. Power System, vol. 11 No. 2, pp. 767-773, May 1996.

[6] System Planning Department, Power Grid Company of Bangladesh Limited. (2009, January). Grid Map. [Online]. Available: http://www.pgcb.org.bd.

[7] P. M. Anderson, and A. A. Fouad, Power System Control and Stability. Indian English Language Edition, Iowa: The Iowa State University Press, Ames, Iowa, USA, 1984.

[8] G. Rogers, Power System Oscillations. 2nd ed., Boston: Kluwer Academic Publishers, 2007.

[9] Nexant, "Power System Master Plan Update 2005",Ministry of Power, Energy \& Mineral Resources, Dhaka,Bangladesh, Asian Development Bank TA No. 4379-BAN: Power Sector Development Program II, Component B,Section-3.

[10] P. Kundur, Power System Stability and Control., New York: McGraw-Hill, 1994

[11] J. Chow, and G. Rogers. (2009, August). Power System Toolbox.

[12] Md. Jan-E-Alam, "Enhancement of Power Transmission Capability of East-West Interconnector Using Controlled Series Compensation", M. Sc. Eng. Thesis, Dept. of EEE. 